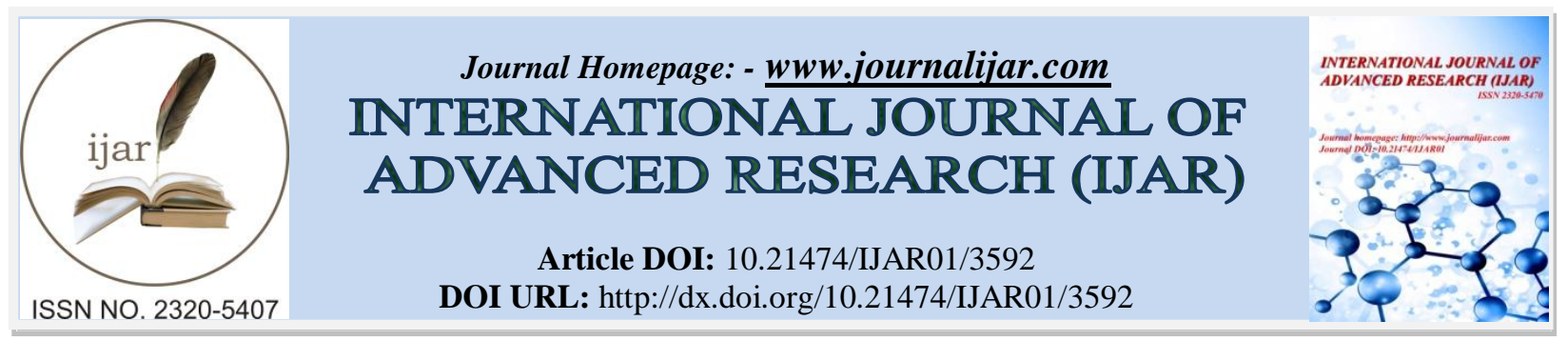

RESEARCH ARTICLE

\title{
A CONTROL STRATERGY FOR THE IMPROVEMENT OF POWER QUALITY IN MICROGRID.
}

*Prajith Prabhakar and Dr. H Vennila.

1. Research Scholar in Electrical \& Electronics Department, NI University.

2. Associate Professor in Electrical \& Electronics Department, NI University.

\section{Manuscript Info}

Manuscript History

Received: 05 January 2017

Final Accepted: 04 February 2017

Published: March 2017

Key words:-

Power Quality, Active power control, microgrid, predictive control,

DSTATCOM.

\begin{abstract}
Model Predictive Controller (MPC) is described in this paper for the improvement of power quality in Microgrids. Microgrid is a low voltage grid which is subjected to disturbances. The distributed energy resources are connected to the LV bus by means of power electronic converters. The power quality issues are analyzed with MPC control algorithm in both- Grid connected \& Islanded modes. But the Islanded mode is analyzed separately. Predictive control based Distribution static compensator (DSTATCOM) injects voltages at the point of common coupling (PCC) in the Microgrid. Reactive power compensation is done with two linear \& one non linear load in both modes of operation. The principles and the proposed algorithm are verified by MATLAB/SIMULINK simulation. Simulation results suggest that this control method can decrease the power quality issues and increase the microgrid stability.
\end{abstract}

Copy Right, IJAR, 2017,. All rights reserved.

\section{Introduction:-}

In traditional power systems, a few large centralized power generation plants produce most of the power and emissions. The generated electric power is then transferred towards large load centers over long distance transmission lines. The system control centers monitor and controls the system continuously to ensure the quality of the power, namely the frequency and the voltage. However, due to the rapid increase in global energy consumption and the diminishing fossil fuels, the demand for new generation capacities and efficient energy production, delivery and utilization is rising. Utilizing renewable energy [1], distributed generation, and energy storage in large scale can potentially solve such problems as energy shortage and global climate change.

A promising structure to interconnect these distributed Energy resources are the microgrid paradigm. A microgrid is a low-voltage distribution system which is subjected to lot of disturbances when non linear loads such as electric arc furnaces, electric arc welders, adjustable speed drives and switch mode power supplies are connected [3]. These loads may generate harmonics and increase the demand of reactive power flow from the renewable energy resources. Microgrids have to be operated isolated from the main grid in case of faults, which are controlled by the Microgrid central controller. The elimination of these power quality issues in the connection with the distributed energy resources can be done by the usage of Series active filters or the Custom power devices (CPD) like DSTACOM , Dynamic voltage restorer(DVR) and Unified power conditioner(UPQC).

Corresponding Author:- Prajith Prabhakar.

Address:- Research Scholar in Electrical \& Electronics Department, NI University. 
Traditionally, inverters used in Microgrids behave as current sources when they are connected to the grid, and as voltage sources when they work autonomously [2]. Currently, most inverters in Microgrids adopt the voltage-source inverter (VSI) topology with a current controller to regulate the current injected into the grid. Current-controlled inverters have the advantages of the high-accuracy control of an instantaneous current, peak-current protection, overload rejection, and very good dynamics. The performance of the VSI depends on the quality of the applied current-control strategy and, in order to meet power quality requirements, inverters in Microgrids should have very good capability in harmonic rejection.

There has been considerable research in the field of power quality issues. The various techniques used in the control of custom power devices for the solution to the active \& reactive power compensations are Instantaneous reactive power theory, Model Predictive control, Modified power balance theory, Enhanced PLL technique, Artificial Neural network.[5].

Predictive control technique has been chosen for the mitigation of issues in the distributed energy resources based microgrid. Three distributed energy resources are being modeled and the DSTATCOM with MPC controller has been injected into the point of common coupling to compensate the active \& reactive power. MPC is an advanced method of process control that allows the time slot to be optimized keeping the future timeslots into account. It has the advantage to anticipate the future events and take control actions accordingly. MPC predicts the change in dependent variables of the modeled system that will be caused by changes in independent variables e.g. reactive power and Harmonics.

\section{EXISTING METHODS}

This section describes the methods that were already implemented in the mitigation of power quality issues in the distribution systems. Different strategies like proportional-integral (PI), proportional-resonant (PR), predictive deadbeat (DB), or hysteresis controllers have been proposed in the control of active and reactive power compensation. The PI control scheme in the synchronously rotating $(d, q)$ reference frame is commonly used and can work well with balanced systems, but it cannot cope with unbalanced disturbance currents, which are common in Microgrids. The PR control scheme in the stationary $(\alpha, \beta)$ reference frame is popular due to the capability of eliminating the steady-state error, while regulating sinusoidal signals, and the possible extension to compensate multiple harmonics. However, the resonant frequency in the controller has to be identical to the varying grid frequency in order to maintain good performance. Hysteresis control is simple and brings fast responses, but it results in high and variable sampling frequencies, which leads to high current ripples, poor current quality, and difficulties in the output filter design. In order to obtain a fixed switching frequency, the complexity of the controller will be increased, if an adaptive band hysteresis controller is used.

Compensation and control strategies to eliminate the influence of non-linear and unbalanced loads on Microgrid and the utility grid that connected based on instantaneous power in d-q reference frame has been proposed [3]. In the paper a reference current is generated for the distributed sources (DS) with the difference between the rated power of DS and the power demand of the local non- ideal loads. The power sharing of the DS are not considered in this paper. Compensation algorithm proposed in this paper was based on instantaneous power theory in abc reference frame. It takes no consideration about the unbalanced loads at PCC which are long distances from any DS in the Microgrid. There were no related studies in the field of Microgrid power quality improvement using this approach. Another paper proposes an algorithm and control, based on instantaneous power in d-q reference frame by considering the non-linear and unbalanced loads in the Microgrid [5]. The reference currents converters are generated with respect to the difference between the instantaneous currents at the distribution network and the load sides. Inverse droop control was proposed to achieve the switching of the operating modes. The paper does not tell anything related to fault analysis mode of Microgrid with the existing method.

The work described in another paper regards the evaluation through numerical simulation, of the inverter-fed MG dynamic behavior under islanded operation for different load conditions and using two different control strategies [11]. Control scheme based on droop concepts to operate inverters feeding a standalone ac system is presented. Two kinds of controlling was used to operate an inverter. PQ inverter control and voltage source inverter control (VSI). In the latter control, inverter was controlled to feed the load with pre-defined values for voltage and frequency. This paper describes and evaluates the feasibility of the control strategies needed for Microgrid (MG) islanded operation, where no directly grid-connected synchronous generators are used. 
A control algorithm based on correlation function approach in DSTATCOM was done in another paper [5]. In this approach, an extraction of fundamental active and reactive power components of load currents is based on correlation and cross correlation functions in time domain. For estimation of fundamental active and reactive power components of load currents, a numerical integration is applied in correlation and cross correlation function. The improvement of the transient response of parallel connected inverters without using the communication signals were proposed in ac distribution system [6]. A wireless controller was developed, by adding supplemental transient droop characteristics to the conventional static droop approach, which improves the paralleled-system dynamics. Several intrinsic problems led to its limited transient response, as the system dynamics depends on the power calculation characteristics. Another new adaptive neuro-fuzzy control method is utilized to achieve smooth bidirectional power flow and nonlinear unbalanced load compensation simultaneously [8]. In this case, the traditional PI controller might be insufficient because of the instantaneous changes in the dynamics of the system. An integrated diagnostic system was developed for islanding detection using a neuro-fuzzy model for grid-tied inverter-based DGs. In a paper, an adaptive neuro-fuzzy inference system was used for islanding detection.

In reference[8], a current control method for inverters based on the sigma delta modulation algorithm called the sigma delta-based current controlled voltage source inverter interfaced with DG generators was studied. A particle swarm optimization method was used for the optimum tuning of the controllers as a result of the existent number of PI controllers. $\Sigma \Delta$ CC__VSI minimizes the harmonics of the unfiltered voltage. Thus, it is powerful in minimizing electromagnetic interference, which is critical for sensitive loads. The development of new control strategies and execution of multifunctional compensation capability are the main research trends related to both active power flow control and mitigation of various PQ disturbances using MFIs.

A previous study analyses the limitations of the standard resonant current control operating under abnormal grid conditions and then introduces a control scheme that improves the current harmonic distortion in such adverse conditions without increasing the computational load of the standard current control[12]. The resonant current control has been extensively employed to reduce the current harmonic distortion in a wide range of DG applications. This control uses a proportional-resonant (PRES) compensator to track the fundamental component of the current reference signal and a resonant harmonic (RESH) compensator to attenuate the most important current harmonics. The main problem of the resonant current control is the performance deterioration given by abnormal conditions in the utility grid. Power quality improvement in micro grids by using Active power conditioner was proposed in another literature [13]. The Active Power Conditioner (APC) acts as an interface between renewable energy sources and the AC bus of a micro grid and uses an APC control strategy, which makes it possible to inject energy in the micro grid, compensate the current harmonics and correct the power factor. Proposed control algorithm is compensation method that makes the APC compensate the current of a non-linear load by forcing the Microgrid side current to become sinusoidal and balanced. Compared with linear controllers, the non-linear ones based on hysteresis strategies allow faster dynamic response and better robustness with respect to the variation of the nonlinear load. A drawback of the hysteresis strategies is the switching frequency which is not constant and can generate a large side harmonics band around the switching frequency. To avoid this drawback, the switching frequency can be fixed using different solutions like variable hysteresis bandwidth or module bandwidth.

\section{Proposed Method:-}

In this section a model of a typical Microgrid is explained that was used to carry out the analysis of the power quality issues. A typical Microgrid is shown in Figure 3.1. 


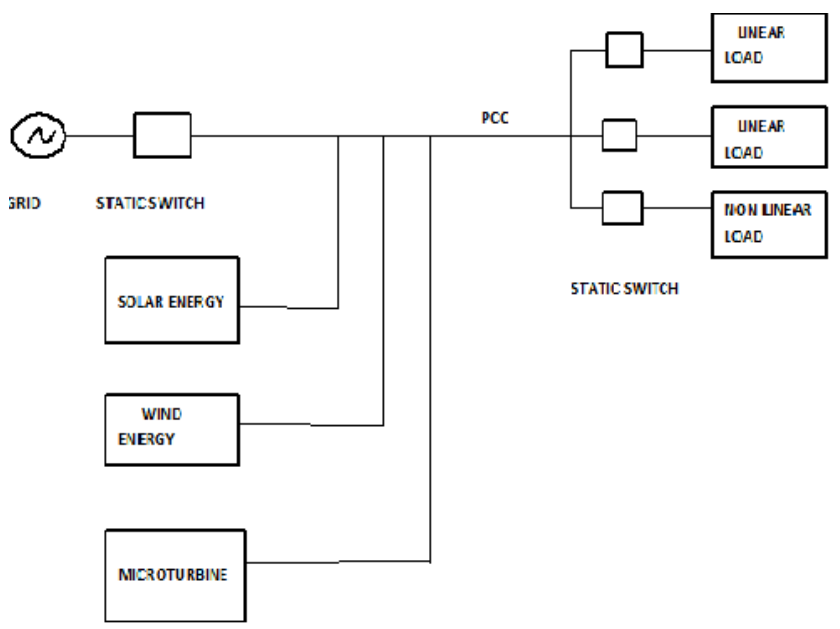

Fig.3.1:- Proposed Microgrid.

In the proposed Microgrid diagram, three distributed energy resources blocks like Solar Energy, Wind Energy and Microturbine are modeled in both Grid connected and Isolated modes of operation. It is then connected to two linear and non-linear loads via a static switch. Linear loads like Incandescent lamps, Heaters etc and the Non- linear loads are SMPS, refrigerators, Television etc. The static switch is closed in grid connected and opened in islanded mode. The compensation of reactive power and harmonics is done by Model Predictive controller (MPC). Each Distributed resources are modeled with the Predictive algorithm separately and added to the point of common coupling.

Model Predictive controller (MPC) concept is most widely used in all modern control techniques. The MPC formulation is based on giving a reasonably accurate model for current system, possible consequences of the current and future manipulated input moves on the future plant behavior and the constraints can be forecasted online and used while deciding the input moves in a optimal manner.MPC has four important tuning parameters which controls the formulation of algorithm. They are weight matrix, the output weight matrix the prediction horizon and the control horizon. Only the first step of the control strategy is implemented, then the model state is sampled again and new calculations are repeated starting from the new current state, yielding new control \& predicted path. MPC starts adjusting the control signal head of the reference changes. This model works in two modes of operation

Grid connected mode: In this mode, Microgrid is connected to the Main grid through a static switch. The references for the DS controller can be obtained from the Grid. The reactive power is compensated with the help of the Predictive control algorithm. The Diagram in the Grid connected mode is shown in figure 3.2.

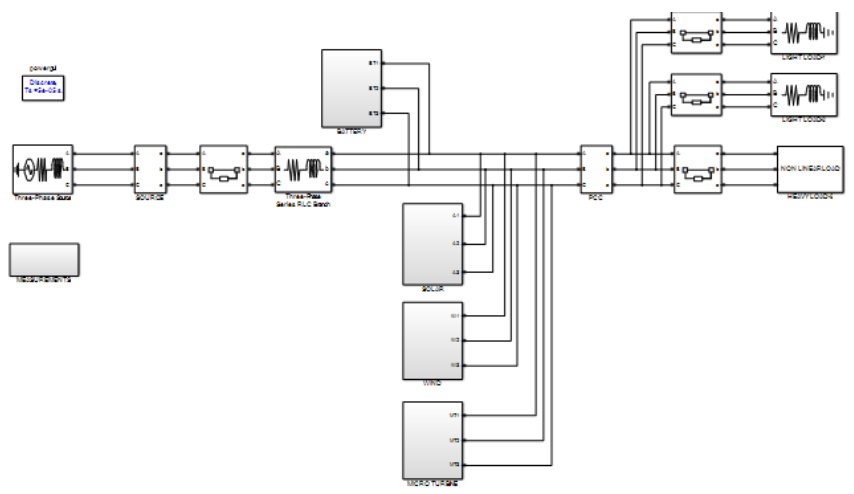

Fig.3.2:- Grid connected mode

Islanded Mode: Islanding of the Microgrid can take place by unplanned events like faults in the grid side or by planned actions like maintenance requirements. In this mode also three DGs are modeled using MPC controller and connected to the PCC. The main grid is disconnected from the Microgrid by using the static switch. In this case, the local generation profile of the microgrid can be modified in order to reduce the imbalance between local load and 
generation. The Microgrid has to work autonomously feeding the loads. MPC generates references for the function of the Microgrid. After 0.2s the Grid is added to the Microgrid. The diagram of the isolated mode is shown in the figure 3.3.

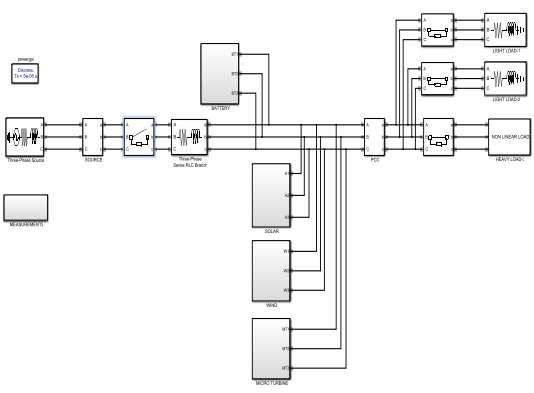

Fig.3.3:- Islanded mode

In the isolated mode of operation due to the presence of non-linear loads all the DG's have to compensate the loads, in the absence of the Grid. The present network has a dominant impact in the quality of power delivered to the loads in the case of Islanded mode while considering the non-linear load. For the improvement of reliability of the present system, a modification in the Microgrid is proposed. DSTATCOM was proposed to be added to the existing system. The need for the CPD in the distribution side of the Microgrid was for the smooth function whose performance was very sensitive to the quality of power delivered to the loads. The result of the nonlinear loads in the distribution side makes the waveform of suppliers to be in the distorted form.

A DSTACOM is a custom power device which is utilized to eliminate the harmonics from the source currents and also balance them in addition to providing reactive power compensation to improve the power factor or regulate the load bus voltage. With the shunt connected controllers (DSTATCOM), it is possible to control the power flow in critical lines. DSTATCOM was also modeled with the Predictive controller to regulate the power flow at the point of common coupling. This system was checked with the two modes of operation and in addition to that fault analysis mode too. The effectiveness of the proposed system was verified using the MATLAB/SIMULNK program.

The Predictive controller is been incorporated in each distributed sources and the DSTATCOM which injects voltages and currents to the point of common coupling in both the modes. MPC controller is shown in figure 3.4.

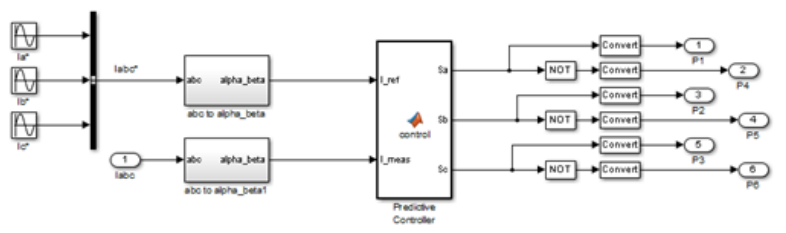

Fig.3.4:- Model Predictive Controller

The reference currents are produced by the MPC by the help of three reference signal constants converted to alphabeta version and is given to the Predictive control block from the Simulink tool box. Actual currents are also sensed and given to the controller block. Controlled output signals will be fed to the PCC from each modeled Distributed resources. Modeled Solar with MPC is shown in the Figure 3.5.

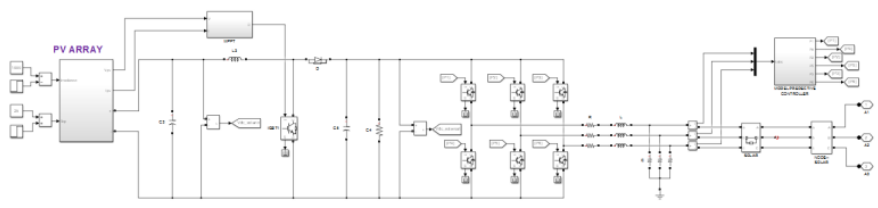

Fig.3.5:- Solar Model with MPC 
It consists of a PV array which is fed to six bridge inverter and given the output to the PCC. The pulses to the thyristors are given from the MPC controller.

\section{Results \& Discussions:-}

The Simulink diagram of the proposed Predictive control based DSTACOM is shown in the figure 4.1.

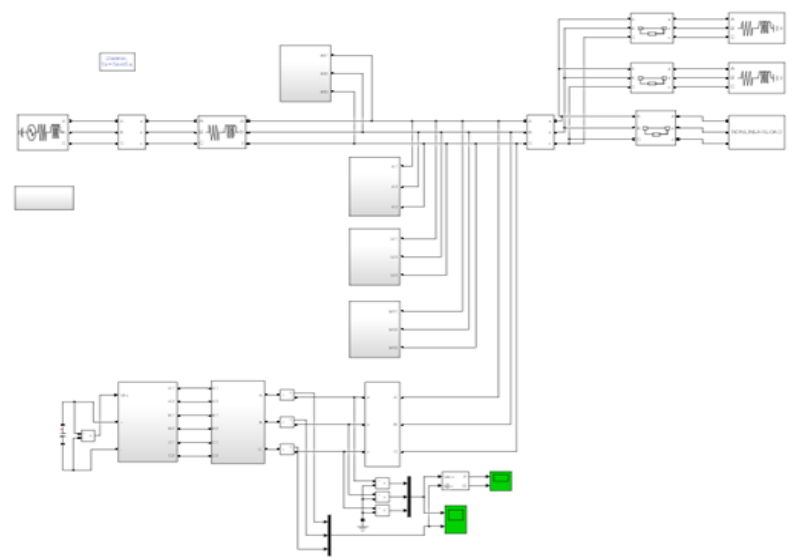

Fig.4.1:- Grid connected mode with DSTATCOM

The test model contains three Distributed energy resources which are modeled with the Predictive controller and the power ratings of the solar and wind models with a varying output of $5 \mathrm{~kW}$ and reactive power of $10 \mathrm{~kW}$ varying with respect to time. Three loads are connected to the PCC with two light loads of $25 \mathrm{~kW}$ each and a non linear load of 18 $\mathrm{kW}$ with 8.5KVAR and 12.3 KVAR respectively. The grid rating is $2500 \times 10^{6} \mathrm{VA}$ and $60 \mathrm{~Hz}$ frequency.

The test micro grid was simulated in two different modes of operation.

\section{Grid Connected mode:-}

The simulation sequence was as follows. Load 1 was decreased from $25 \mathrm{~kW}$ and $18 \mathrm{~kW}$ to $20 \mathrm{~kW}$ and $10 \mathrm{~kW}$ at $1.2 \mathrm{~s}$ to investigate power sharing in terms of load variation during grid-connected operation. At $2.0 \mathrm{~s}$, the static switch was opened so that the Microgrid was islanded from the grid. Output Active \& Reactive power at the Grid and load side is shown in the simulation graphs from the figure $4.2 \& 4.3$.

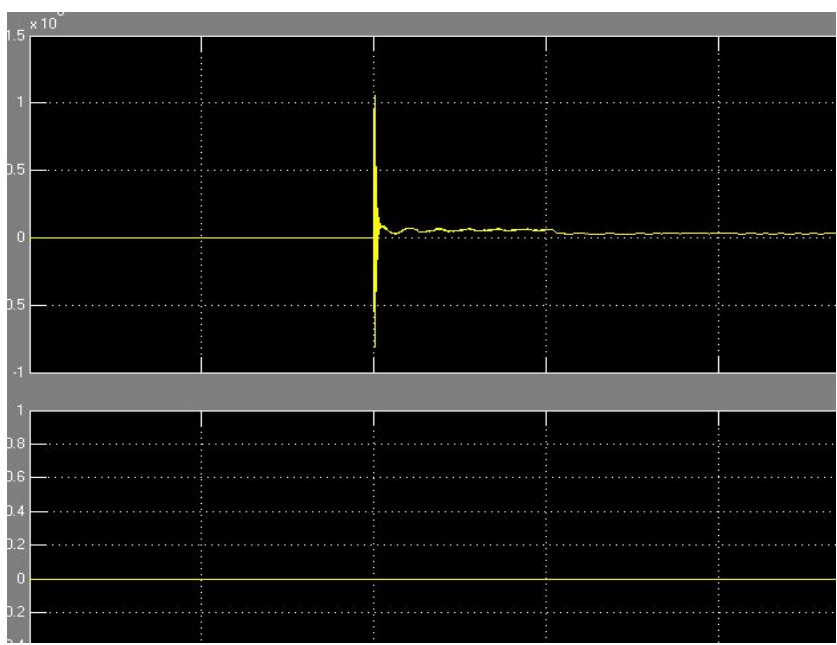

Fig 4.2:- Grid Side Active \& Reactive power 


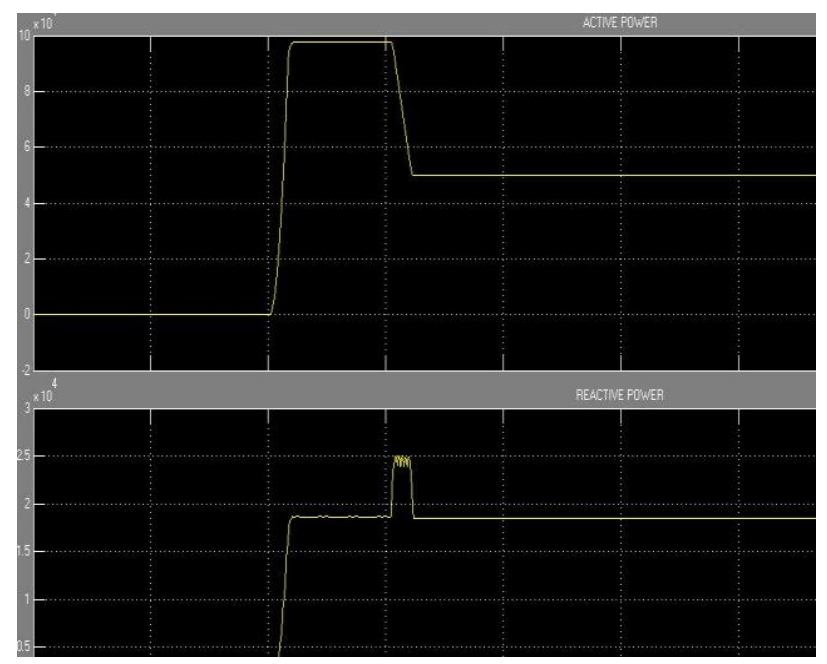

Fig .4.3:- Load side Active \& Reactive power

From the above shown graphs, when all the loads are connected to the grid the active power becomes $95 \mathrm{~kW}$ and reactive power becomes 190 kvar with a small spike.

\section{Islanded Mode:}

The static switch was opened and the grid will be disconnected from the AC bus. Load is being varied to appropriate values. The IGBT inverters which are modeled in each Distributed sources with the MPC will operate in Islanded mode. If there is any decrease in the DG output to load, the controller compensates the DS output. Figure4.4 shows the Microgrid operation in Isolated mode of operation.

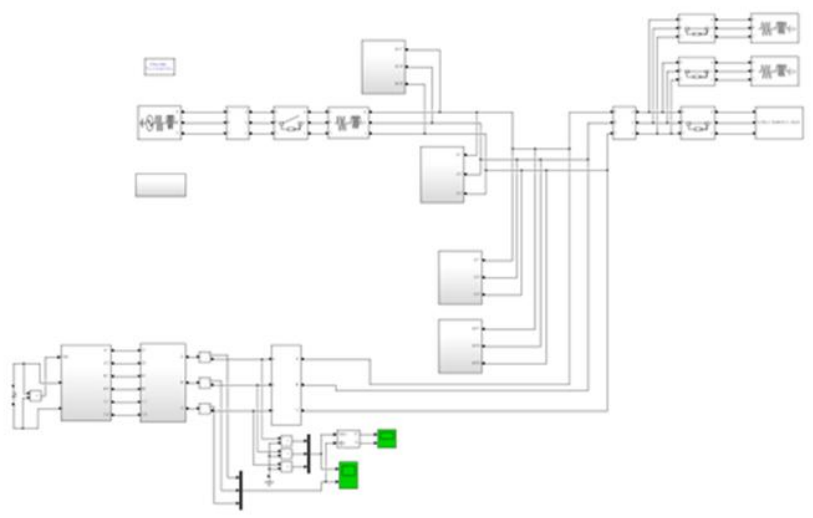

Fig.4.4:- Islanded Mode with DSTATCOM

In the islanded mode of operation, when all the loads are connected to Microgrid, load power is compensated by the MPC based DSTCOM at the PCC. From the figure 4.5..a. It's clear that the DSTATCOM compensates the active and reactive power in the Islanded mode up to $0.2 \mathrm{~s}$ of the Microgrid and loads. Its negative value is of $2.5 \times 10^{\wedge} 4$ $\mathrm{VAr}$ of reactive and $500 \mathrm{~W}$ of active power. Figure 4.5 shows the load side Active and reactive power in the Isolated mode of operation. 


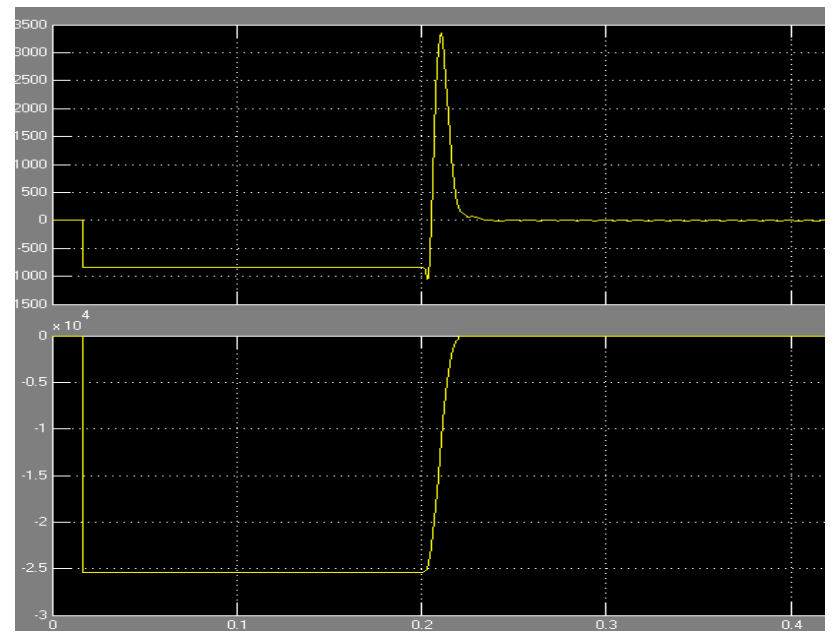

Fig.4.5.a:- DSTATCOM output in Islanded Mode

Voltage variations were seen in this mode of operation when non-linear load is connected. This is shown in the figure 4.5.b.

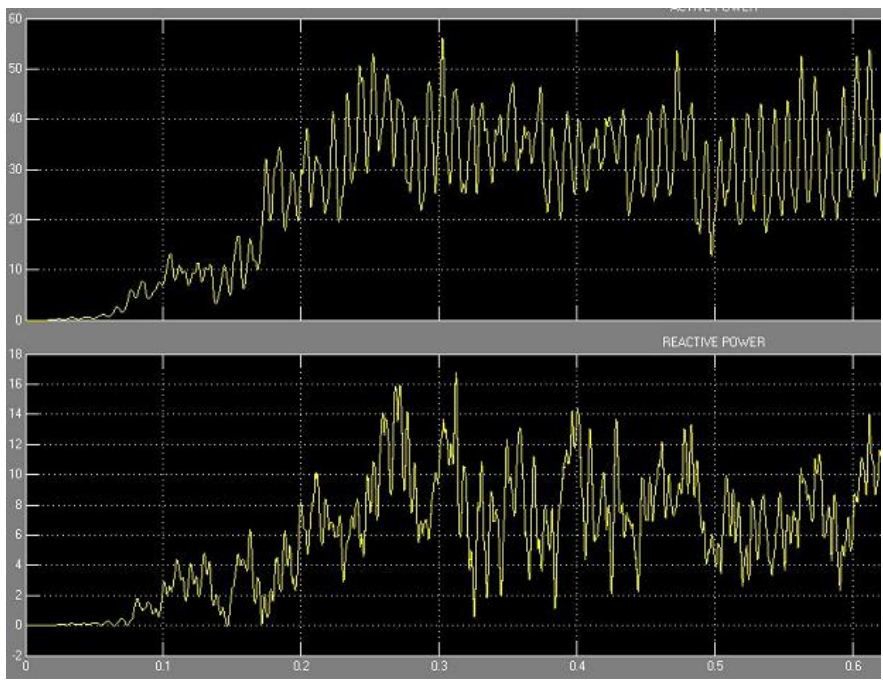

Fig.4.5.b:- load side active and reactive power

Due to the presence of second order harmonics with Non-linear load in the isolated mode of operation all the DG's are connected to a single modelled structure as shown in Figure 4.6 to improve the system stability when the Grid is disconnected.

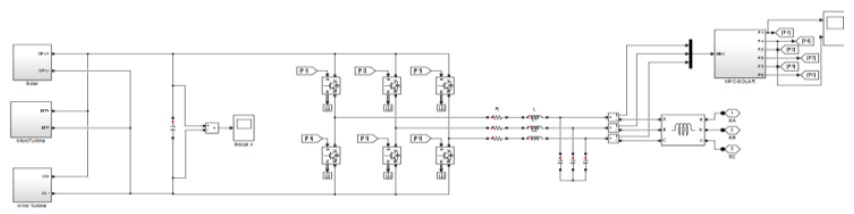

Fig.4.6:- Incorparated view of DG's

All the modeled DG's are connected to a single MPC controller and it has been connected to the point of common coupling (PCC) with the DSTATCOM. The output of the current view is shown in the figure 4.7. It is clear that Reactive power is being compensated in the islanded mode of operation completely. Negative reactive power is caused by capacitive loads that include lighting ballasts, variable speed drives for motors, computer equipment, and inverters. 


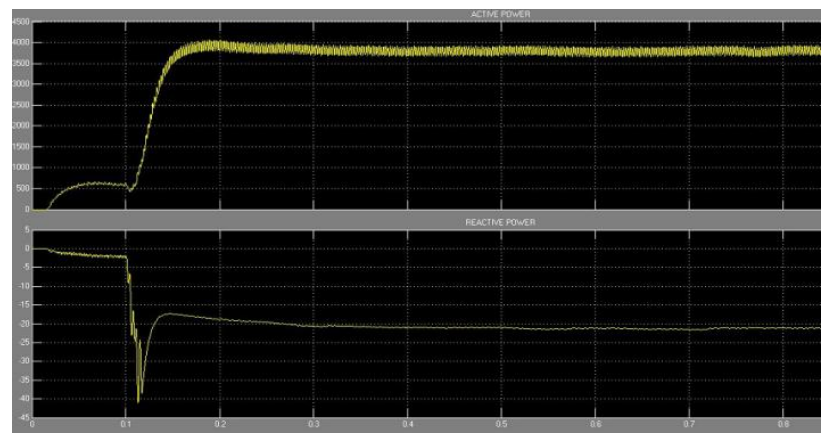

Fig.4.7:- Load active and Reactive power.

\section{Conclution:-}

In this paper an MPC based DSTATCOM was implemented in the Microgrid. The Microgrid reliability and the compensation of the reactive power were examined with the simulation results. Predictive controller was successfully implemented in the Distributed resources and the power quality issues were studied, analyzed and compensated in the proposed Microgrid. The control algorithm was implemented in the conventional distribution system; it is also applicable in the case of Microgrids too. MPC based DSTATCOM was incorporated in the Microgrid and comparative results were done in both Grid connected and Islanded modes with the help of Simulation. In

Grid-connected mode, DGs compensates the non-linear and unbalanced loads and shares with utility grid in a pre specified ratio. During islanded mode harmonics were present on the system with non-linear load, on basis of the future analysis advantage characteristics and the variations of voltage and frequency, an incorporated view is being suggested and the satisfactory results were produced. Battery source was also added to the Microgrid to compensate the loads in the islanded mode. MPC offers a good improvement from the conventional PI and PR controllers in the presence of linear and non linear loads. A future development is to check the MPC controllers with the fault analysis mode in the proposed Microgrid.

APPENDIX
\begin{tabular}{|l|l|}
\hline DC VOLTAGE & $400 \mathrm{~V}$ \\
\hline SWITCH FREQUENCY & $16 \mathrm{~Hz}$ \\
\hline GRID VOLTAGE & $400 \mathrm{kV}, 2500 \mathrm{MVA}$ \\
\hline VOLTAGE IN ISLAND & $390 \mathrm{kV}, 60 \mathrm{~Hz}$ \\
\hline LIGHT LOAD1 & $25 \mathrm{~kW}, 8.5 \mathrm{kVAr}$ \\
\hline LIGHT LOAD2 & $25 \mathrm{~kW}, 10 \mathrm{kVAr}$ \\
\hline NONLINEAR LOAD & $18 \mathrm{~kW}, 12.3 \mathrm{kVAr}$ \\
\hline X/R RATIO & 10 \\
\hline $\mathrm{V}_{\mathrm{dc}}$ & $350 \mathrm{~V}$ (Vary) \\
\hline
\end{tabular}

\section{References:-}

1. V. Akhmatov and P. B Eriksen, "A Large Wind Power System in Almost Island Operation-A Danish Case Study", IEEE Transactions on Power Systems, Vol. 22, No. 3, pp. 937 - 943, Aug. 2007.

2. B. C. Ummels, M. Gibescu, E. Pelgrum, W. L .Kling, and A. J. Brand, "Impacts of Wind Power on Thermal Generation Unit Commitment and Dispatch", IEEE Transaction on Energy Conversion, Vol. 22, No. 1, pp. 44 51, March 2007

3. J.A Pecas Lopes, C.L Moreira, A.G Madueria "Defining Control Strategies for Microgrids Islanded Operation" , IEEE TRANSACTIONS ON POWER SYSTEMS, VOL. 21, NO. 2, MAY 2006

4. J. Ribrant and L. M. Bertling, "Survey of Failures in Wind Power

5. Systems with Focus on Swedish Wind Power Plants During 1997-2005", IEEE Transaction on Energy Conversion, Vol. 22, No.

6. 1 , pp. $167-173$, March 2008. 
7. Bhim Singh, Sabha Raj Arya ," Design and control of a DSTATCOM for power quality improvement using cross correlation function approach", International Journal of Engineering, Science and Technology Vol. 4, No. 1, 2012, pp. 74-86.

8. Milan Prodanovic, Timothy C Green, "High-Quality Power Generation Through Distributed Control of a Power Park Microgrid" , IEEE TRANSACTIONS ON INDUSTRIAL ELECTRONICS, VOL. 53, NO. 5, OCTOBER 2006.

9. Y. Li, D. M. Vilathgamuwa, and P. Loh, "Design, analysis, and real-time testing of a controller for multibus microgrid system", IEEE

10. Transactions on Power Electronics, Vol. 19, No. 5, pp. 1195 - 1204,

11. Sept. 2004.

12. Ahmet Teke, Mohammad Barghi Latran, "Review of Multifunctional Inverter Topologies and Control Schemes Used in Distributed Generation Systems", Journal of Power Electronics, Vol. 14, No. 2, pp. 324-340, March 2014.

13. N. Hatziargyriou, H. Asano, R. Iravani, and C. Marnay, "Microgrids", IEEE Power and Energy Magazine, Vol. 5, No. 4, pp. 78 - 94, July-Aug. 2007.

14. Tuladhar, J. Hua, T. Unger, and K. Mauch, "Control of parallel inverters in distributed AC power systems with consideration of line Impedance effect", IEEE Transactions on Industry Applications, Vol. 36, No. 1, pp. 131 138, Jan.-Feb. 2000

15. J. M. Guerrero, L. Vicuna, J. Matas, M. Castilla, and J. Miret, "A Wireless controller to enhance dynamic performance of parallel inverters in distributed generation systems", IEEE Transactions on Power Electronics, Vol. 19, No. 5, pp. 1205 - 1213, Sept. 2004

16. Miguel Casilla, Jaume Miret, Antonio Camacho ," Reduction of Current Harmonic Distortion in Three-Phase Grid-Connected Photovoltaic Inverters via Resonant Current Control", IEEE TRANSACTIONS ON INDUSTRIAL ELECTRONICS, VOL. 60, NO. 4, APRIL 2013

17. S. Swetha, B. Subhas, "Power Quality Improvement in Microgrid Using Active Power Conditioner", INTERNATIONAL JOURNAL

18. OF PROFESSIONAL ENGINEERING STUDIES Volume I/Issue I/DEC 2013.

19. Yunwei Li, D. Mahinda Vilathgamuwa, Poh Chiang Loh, "Microgrid Power Quality Enhancement Using a Three-Phase Four-Wire Grid-Interfacing Compensator", IEEE TRANSACTIONS ON INDUSTRY APPLICATIONS, VOL. 41, NO.6 NOVEMBER/DECEMBER 2005

20. Chandana Jayampathi Gajanayake, , D. Mahinda Vilathgamuwa, Poh Chiang Loh, , Remus Teodorescu, Frede Blaabjerg," Z-Source-Inverter-Based Flexible Distributed Generation System Solution for Grid Power Quality Improvement", IEEE TRANSACTIONS ON ENERGY CONVERSION, VOL. 24, NO. 3, SEPTEMBER 2009.

21. Jeena John, K Navatha Kumari ,"Model Predictive approach for power quality improvement in distributed generation Inverter", INTERNATIONAL JOURNAL OF ADVANCED RESEARCH IN SCIENCE AND ENGINEERING, VOL.04, ISSUE 04, APRIL 2015. 